\title{
Optimisation of carbon capture from flue gas from a Waste- to-Energy plant using surrogate modelling and global optimisation
}

\author{
Anders Andreasen* (D) \\ Ramboll Energy, Field Development, Studies and FEED, Bavnehøjvej 5, 6700 Esbjerg, Denmark
}

Received: 14 March 2021 / Accepted: 14 June 2021

\begin{abstract}
The optimisation of Post Carbon Capture (PCC) from a Waste-to-Energy plant has been studied using Kriging surrogate models trained from a set of rigorous process simulations. The surrogate models allow fast and efficient calculation of model responses required for the optimisation of operating parameters. Optimisation is performed using Differential Evolution (DE) requiring a vast amount of function calculations $(>1000)$ which would be extremely time consuming if done with a rigorous process simulation model. It is found that for meeting a $\mathrm{CO}_{2}$ removal efficiency of $85 \%$ for a flue gas containing 12.6 mole $\% \mathrm{CO}_{2}$ and a reboiler temperature limited to max. $120{ }^{\circ} \mathrm{C}$, a L/G ratio of approx. $2.2(\mathrm{~kg} / \mathrm{kg})$ is optimal. This is accompanied by a stripper/regenerator pressure of 1.85 bara, a temperature of the flue gas at the lower bound, a temperature approach of the lean amine entering the absorber of $6.5^{\circ} \mathrm{C}$ (to the flue gas temperature), and a temperature approach in the $\mathrm{L} / \mathrm{R}$ heat exchanger of $5{ }^{\circ} \mathrm{C}$. The optimal lean and rich amine loading is approx. 0.21 and 0.52 (mole $\mathrm{CO}_{2} /$ mole MEA).
\end{abstract}

\section{Nomenclature}

$\begin{array}{ll}\text { ANN } & \text { Artificial Neural Network } \\ \text { API } & \text { Application Programming Interface } \\ \text { BECCS } & \text { Bio-energy with Carbon Capture and Storage } \\ \text { CCS } & \text { Carbon Capture and Storage } \\ \text { CAPEX } & \text { Capital Expenditure } \\ \text { COBYLA } & \text { Constrained Optimization BY Linear } \\ & \text { Approximations } \\ \text { COM } & \text { Component Object Model } \\ \text { DE } & \text { Differential Evolution } \\ \text { dT } & \text { Temperature difference } \\ \text { IPCC } & \text { Intergovernmental Panel on Climate Change } \\ \text { L/G } & \text { Liquid to Gas ratio } \\ \text { LHS } & \text { Latin Hybercube Sampling } \\ \text { L-R } & \text { Lean/Rich (amine) } \\ \text { MEA } & \text { Mono Ethanol Amine } \\ \text { NLP } & \text { Non-Linear Programming } \\ \text { NPV } & \text { Net Present Value } \\ \text { nRMSE } & \text { normalised RMSE } \\ \text { NRTL } & \text { Non-Random Two Liquid } \\ \text { NSGA } & \text { Non-dominated Sorting Genetic Algorithm } \\ \text { PCC } & \text { Post Combustion (Carbon) Capture } \\ \text { RMSE } & \text { Root Mean Square Error }\end{array}$

RSM Response Surface Methodology

SLSQP Sequential Least SQuares Programming

SQP Sequential Quadratic Programming

VBA Visual Basic for Applications

VLE Vapour Liquid Equilibrium

WtE Waste to Energy

\section{Introduction}

According to IPCC [1] some extent of Carbon Capture and Storage (CCS) is required in order to limit global warming to $1.5^{\circ} \mathrm{C}$, either to neutralize emissions from sources with no mitigating measures or to achieve net negative emissions. In particular in relation to bioenergy, carbon capture can lead to net negative $\mathrm{CO}_{2}$ emissions, this is also referred to as BECCS [2]. Waste to Energy (WtE) e.g. combustion/ incineration of waste material such as e.g. municipal waste can be considered BECCS due to a high biogenic carbon content [3, 4], and thereby potentially contribute with net negative emissions if equipped with carbon capture technology with sufficiently high $\mathrm{CO}_{2}$ removal efficiency. To achieve post combustion capture of $\mathrm{CO}_{2}$, amine based scrubbing of flue gas with subsequent stripping of $\mathrm{CO}_{2}$ from the amine solution is perhaps the most applied and mature technology. Mono-Ethanol Amine (MEA) is often applied, but a significant challenge also applicable to other amines,

\footnotetext{
* Corresponding author: anra@ramboll.com
} 
is the relatively large amount of energy required to regenerate the amine [5].

The optimisation of amine based $\mathrm{CO}_{2}$ capture from flue gas is of paramount importance and improvements are required in order to reduce the cost of $\mathrm{CO}_{2}$ removal [6]. Reducing energy requirement and CAPEX has been the subject of numerous studies using rigorous process simulation models, see e.g. [7-14]. Optimisation of $\mathrm{CO}_{2}$ capture using amine absorption utilising process simulations is a complex task. The underlying models describing the VLE behaviour as well as the absorption/stripper column models are complex, and solving a complete flow-sheet including all unit operations can be tedious and time consuming, and convergence may not always be achieved. In order to enable optimisation, often requiring thousands of flow-sheet evaluations with different input each time, a robust model is required. By representing the complex process simulation by a surrogate (or reduced order) model, this can be achieved. Furthermore, such surrogate models can be considerably faster to evaluate, compared to converging a flow-sheet solver, as well as either numerical or analytical derivatives can be provided expanding the range of available optimisation algorithms.

Several studies have been devoted to formulating surrogate models or reduced order models for carbon capture systems. Li et al. developed a model for an MEA based process using extreme learning machine trained to simulated data from gProms [15] and also using a deep belief network [16]. Chan and Chan [17] trained an Artificial Neural Network (ANN) also utilising a piece-wise linear algorithm to experimental data, considering eight factors (independent variables) and four responses modelled. Plesu et al. [18] developed a surrogate model for the MEA VLE data using multiple linear regression models.

The aforementioned methods were not used in the context of optimisation for e.g. minimisation of energy requirement or maximising $\mathrm{CO}_{2}$ removal efficiency. Nuchitprasittichai and Cremaschi [19] used a response surface model (multiple regression models) as a surrogate model in order to minimize the cost per mass unit $\mathrm{CO}_{2}$ removed. Wilhelm et al. [12] developed a response surface surrogate model using process simulation and two independent variables and made model adjustments based on experimental data for minimizing the energy requirement. Mores et al. [7] developed a phenomenological mathematical model of $\mathrm{CO}_{2}$ capture using MEA, validated against experimental data and process simulation and optimised the model for various targets using a local Non-Linear Programming (NLP) optimisation algorithm. Neveux et al. [8] used a surrogate model based on ANN for representing the absorption column and utilising a Sequential Quadratic Programming (SQP) algorithm for minimizing the total equivalent work required for $\mathrm{CO}_{2}$ absorption and compression. Lee et al. [9] used an approach where an Aspen Plus simulation model was coupled to a multi-objective optimisation algorithm (NSGA-II), but also noted that a significant fraction of simulation evaluation failed to converge or were otherwise infeasible. Chung and Lee [14] developed a reduced order model fitted to simulated input-output data and utilised it for minimising the $\mathrm{CO}_{2}$ avoidance cost.
In this paper we investigate the optimisation of an MEA based $\mathrm{CO}_{2}$ capture process on a WtE plant using surrogate models for selected model responses. The surrogate models are trained using multiple simulation runs according to a Latin Hybercube Sampling (LHS) plan known from Design and Analysis of Computer Experiments (DACE). Compared to previous studies the present work is novel by combining a relatively large number of factors (independent variables) with a global optimisation algorithm. A framework of automatic simulation runs from a sampling plan with subsequent surrogate model training is presented. The trained surrogates are validated against an independent simulation test set. The trained and validated surrogate models are used for optimisation with the target of minimising the reboiler specific energy requirement subject to variable bounds as well as constraints in model responses. The framework presented is very general and can easily be modified with an even more rigorous simulation model for generating the training set. It can be expanded with an increased number of variables, responses and constraints. Furthermore, the surrogate model applied can be changed to other choices.

\section{Methods}

\subsection{Simulation model}

The process simulations are carried out using AspenTech HYSYS v10 (Aspentech, MA, USA) using the amine property package [20]. The property package uses the Peng-Robinson equation of state [21] for vapour phase and the electrolyte NRTL [22] model for the liquid phase.

The process flow diagram for the modelled process, implemented in the process simulation software, is shown in Figure 1. The flue gas at atmospheric pressure from the Waste to Energy facility is taken as dry flue gas with a composition and flow rate as shown in Table 1. A saturate unit operation ensures that the flue gas is saturated with water vapour at the given inlet temperature to the absorber corresponding to the conditions after a flue gas condensation stage. The wet flue gas enters the absorber at the bottom stage and flows upwards in counter-current flow with MEA which enters the absorber at the third stage from the top. The top two stages are devoted to a water wash section included to minimise MEA losses, but otherwise not used actively in the present study. The flue gas, partially cleaned from $\mathrm{CO}_{2}$, leaves the top of the absorber.

The MEA which has been in contact with the $\mathrm{CO}_{2}$ containing flue gas leaves the bottom of the absorber and is denoted rich amine/rich MEA. The rich amine is pumped to the desired pressure necessary in the amine regenerator unit, which consists of a reboiled stripping column with a top condenser. Before entering the stripping column the rich amine is heated by hot lean amine leaving the regenerator unit in the L-R heat exchanger. In the regenerator which is operated above atmospheric pressure, the temperature is increased in order to regenerate the amine i.e. desorption/stripping of $\mathrm{CO}_{2}$. The supplied heat enables $\mathrm{CO}_{2}$ to desorb from the rich amine. The amine (partially) 


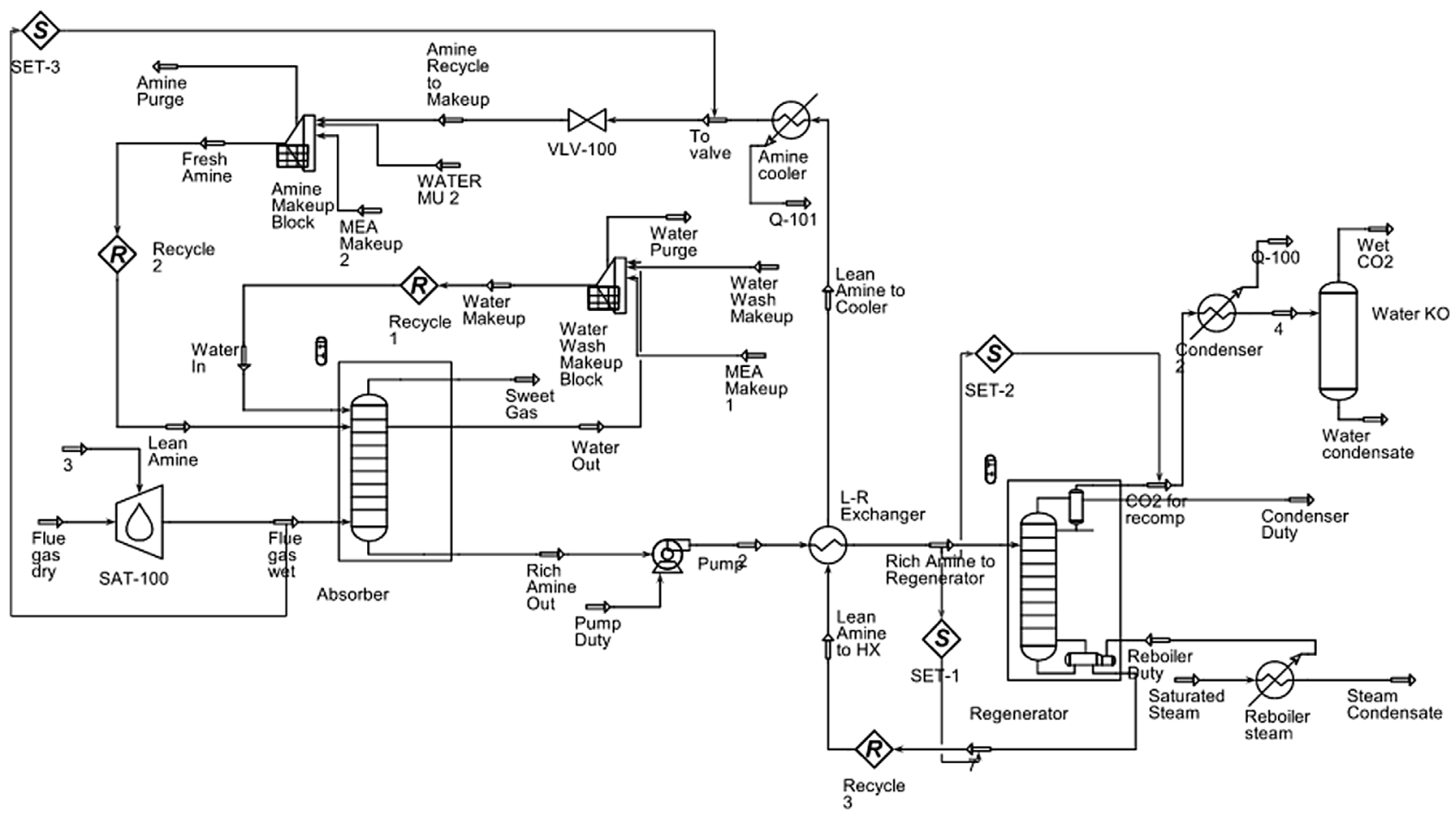

Fig. 1. Process flow diagram modelled in the process simulation software.

Table 1. Dry flue gas composition and flow rate.

\begin{tabular}{lc}
\hline Component & Concentration (mole \%) \\
\hline Nitrogen & 0.805 \\
Oxygen & 0.069 \\
Carbon dioxide & 0.126 \\
Flow rate & $165,600 \mathrm{~kg} / \mathrm{h}$ \\
& $129,208 \mathrm{Sm}^{3} / \mathrm{h}$ \\
\hline
\end{tabular}

stripped from $\mathrm{CO}_{2}$ is referred to as lean amine. After the lean amine from the regenerator unit has cross-exchanged heat with the rich amine it is cooled further down to a temperature slightly above the temperature of the wet flue gas. Before entering the absorber the lean amine passes through an amine make-up block which ensures that the concentration of MEA is as specified, and the recirculation rate of the amine solution is also controlled in this unit operation.

The factors i.e. independent variables considered in the present study are summarised in Table 2 . The reboiler temperature is implicitly given at the applied regenerator pressure in order to give the boil-up ratio specified. Ideally, all variables in such a study shall be independent and directly manipulated. However, the reboiler temperature in combination with the reboiler pressure cannot be independently set. For instance if a temperature is chosen below the bubble point at the applied pressure, no vapour phase will exist in the regenerator and the unit cannot solve. From an operator point of view, using the reboiler temperature as a variable would be preferred, but in the context of the present study where parameters are varied independently to cover as large a fraction of the parameter space as possible, this is not possible, without introducing constraints already during the phase of formulating the sampling plan. This is indeed a possible strategy, but due to its inconvenience it has been discarded in the present study.

The absorber in the simulation model is modelled with 10 stages $(+2$ for the water wash section), in order to improve the solver speed and stability [23]. A fixed stage efficiency is set, but scaled up to a constant value of 0.25 for all stages in order to compensate for the reduced number of stages. The stripper is modelled with 10 stages with a stage efficiency of unity. The applied approach is following the one outlined in ref. [24] also with respect to column solver settings. For simplicity pressure drops in columns and equipment are not modelled.

\subsection{Sampling and surrogate modelling}

A surrogate model of the complex process simulation model is constructed by running the process simulation model for each record in a sampling plan. For each sample the process parameters are varied, and a combination of the sampling plan with the recorded simulation output serves as input for the surrogate model training.

The sampling plan is generated as an optimized LatinHypercube [25, 26] by the pyKriging package [27]. Appropriate sampling of the parameter space is important in order to obtain a good quality of the surrogate model trained to the simulation responses [28]. Others suggest that for up to 10 variables a sampling size of $10-15$ times the number of variables should suffice $[29,30]$. In the present study a sampling size 20 times the number of variables 
Table 2. Independent model variables (factors) and applied range.

\begin{tabular}{lccc}
\hline Variable & Unit & Low & High \\
\hline Flue gas temperature & ${ }^{\circ} \mathrm{C}$ & 40 & 50 \\
MEA recirculation rate & $\mathrm{m}^{3} / \mathrm{h}$ & 300 & 700 \\
MEA concentration & $\mathrm{w} / \mathrm{w} \%$ & 20 & 30 \\
L-R heat exch. min. approach. & $\circ \mathrm{C}$ & 5 & 15 \\
Regenerator pressure & $\mathrm{bar}$ & 1.5 & 3 \\
Lean MEA temperature & $\circ \mathrm{C}$ & 0 & 10 \\
Reboiler boil-up ratio & mole/mole & 0.04 & 0.4 \\
\hline
\end{tabular}

has been applied, which has previously been used by the author [31] with good experience.

An automated process of running all the computer experiments defined by the sampling plan is made combining the process simulator with Python (programming language) via COM (Microsoft Component Object Model) [32]. A black-box wrapper is made in Python exposing the process simulation as an object which can be called like a regular function, taking the seven factors/variables as input, and returning the desired output when the simulation has converged. A similar black-box approach has been used by others [31, 33-36] using either VBA, python or Matlab/Octave as programming layer. For each sample in the sampling plan a corresponding simulation is made and the results recorded.

The object function wrapper exposing the process simulation within Python has built-in a number of restart methods in case the simulation fails to converge. The following three levels of attempts to achieve convergence are implemented; the first level resets the specifications of the $\mathrm{L} / \mathrm{R}$ heat exchanger from specified min. temperature approach to a specified rich amine outlet temperature, waits for convergence, and then resets back to specified min. temperature approach and waits for the solver to converge; the second level is entered if the first level fails, which closes the simulation and reopens it and solves using the provided input; if the second level also fails a high objective function value is returned to force the solver away from this apparent infeasible region. The first level is quite specific to the simulation case in the present work, and is based on experience, that this is the unit operation most prone to fail or to prohibit the entire flow-sheet from solving.

The sampling plan and recorded simulation model output is used to train a Kriging model [37-39] using the pyKriging package $[27,40,41]$. See also [31, 34, 42, 43] for other examples and more information about Kriging in chemical engineering applications.

\subsection{Optimisation}

A general optimization problem is considered:

$$
\min (f(x)) \text {. }
$$

Subject to the constraints

$$
g_{i}(x)=0 \quad \text { for } i=1, \ldots, p,
$$

$$
\begin{gathered}
h_{i}(x) \geq 0 \quad \text { for } i=1, \ldots, q, \\
L_{r}<x_{r}<U_{r} \text { for } r=1, \ldots, n .
\end{gathered}
$$

The objective function $f(x)$ is minimized, subject to $p$ equality constraints $g(x), q$ inequality constraints $h(x)$, and $n$ bounds (upper and lower) on the variables. For the present application the optimisation problem is a global optimisation problem and analytical derivatives are not available directly from the process simulation. Numerical derivatives can be estimated, however, it is often experienced that process simulators based on sequential solvers which include tear-streams/recycles can generate noise in the numerical derivatives due to the applied tolerances $[31,33,34]$. Noise can be reduced by setting extremely low tolerances for the solving of tear-streams, but this comes at the expense of a significantly increased number of iterations for solving the flow sheet and may not be desired. For that purpose derivative-free optimisation routines are required. On the other hand when applying surrogate models numerical derivatives obtained from the surrogate can be smooth and this can also enable choosing derivative based algorithms, with numerical estimates of the derivatives being used [31, 44].

The optimisation is performed with the Differential Evolution algorithm [45-47] which is a global stochastic population based optimisation algorithm (evolutionary algorithm). The implementation is used as-is from the ScIPy library [48]. The population size is set to 105 (default $15 \cdot n$, where $n$ is the number of factors/variables), all other parameters related to population evolution across generations are using the default values. Once the optimisation has converged the converged solution is used as starting point for a polishing step using a local optimisation method. The following methods are applied: Sequential LeastSQuares Programming (SLSQP) [49], the trust-constr trust-region method [50], Constrained Optimization BY Linear Approximation (COBYLA) [51, 52], all as implemeted in the ScIPy library.

For all the above tasks the following python tools and libraries are used: NumPy [53], SciPy [48], Pandas [54], Statsmodeis [55], pyKRiging [27], LHS-MDU [56], pywin32 [57] and Matplotuib [58].

\section{Results}

\subsection{Surrogate model validation}

The Kriging surrogate models for the seven responses trained to the Latin Hybercube Sampling have been compared to the full simulation model. A test plan with 35 samples generated with a random/Monte Carlo sampling plan has been used for the input. The Monte Carlo sampling plan has not been used in the training of the surrogate models. Output is generated with the full simulation model and the Kriging surrogate models, respectively. In Figures 2 and 3 the output of the surrogate model is depicted vs the output from the full simulation model. One graph is shown for each of the responses. As noted from Figure $2 \mathrm{~b}$ many of the computer experiments have 


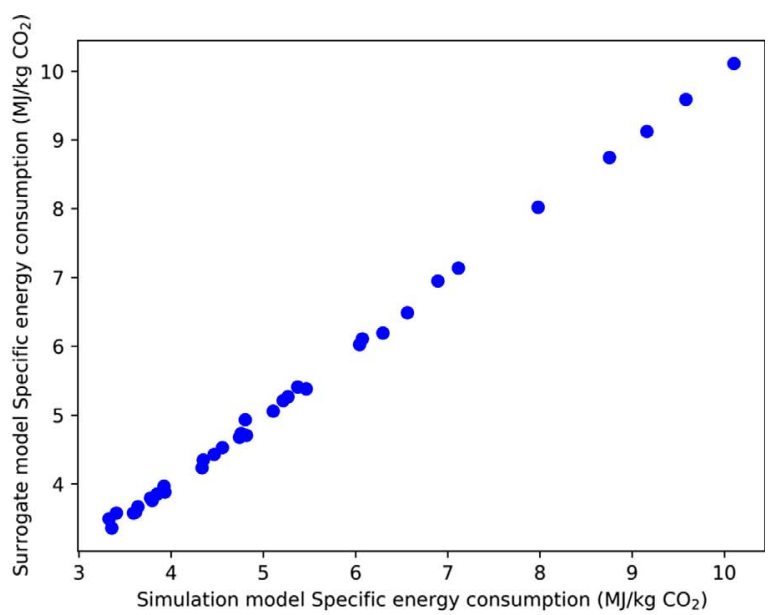

(a)

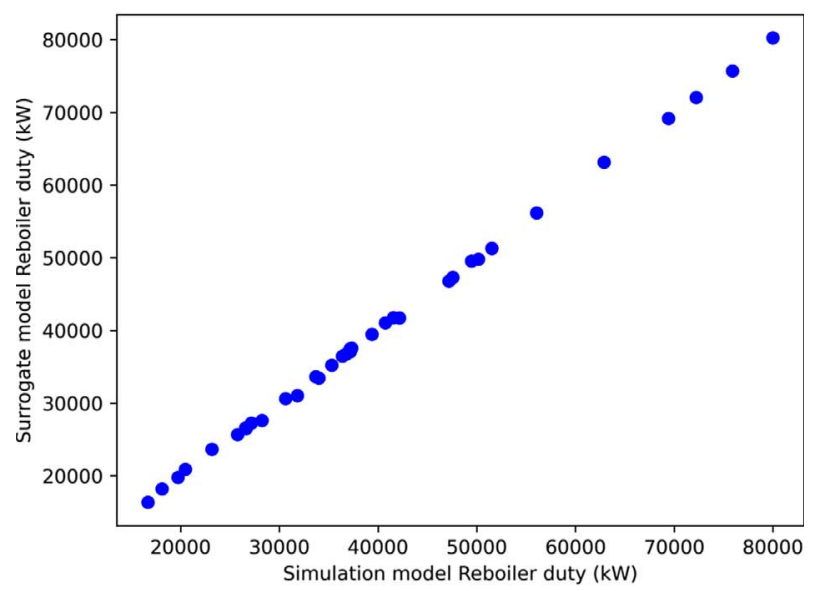

(b)

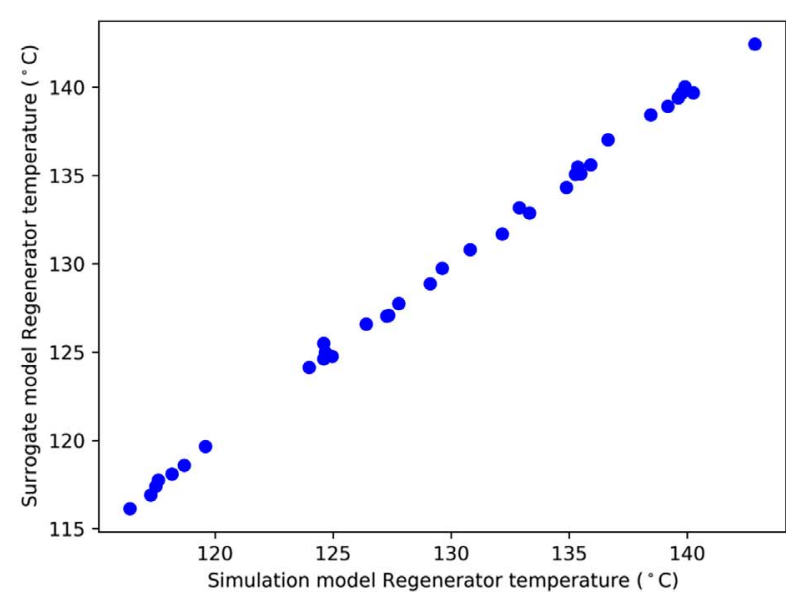

(c)

Fig. 2. Surrogate model response vs. full simulation model response for (a) $\mathrm{CO}_{2}$ specific energy consumption (for reboiler), (b) reboiler duty and (c) reboiler temperature.

a regenerator temperature above the normal recommended maximum of $120^{\circ} \mathrm{C}$. This is mainly a consequence of either a high applied regenerator pressure, a high boil-up ratio or both, and the fact that no constraints have been applied during the formulation of the surrogate model.
Based on the test set, descriptive statistics are calculated for each of the responses. Both $R^{2} / R_{\text {adj }}^{2}$ and the Root Mean Squared Error reported in Table 3 indicate that the surrogate models explain most of the variance in the responses. Judging from the $R^{2} / R_{\text {adj }}^{2}$ and Figures $2-3$ it seems that the $\mathrm{CO}_{2}$ removal rate is the response which is explained the poorest by the surrogate model.

\subsection{Optimisation}

The trained Kriging surrogate models are used for optimising the settings of the $\mathrm{CO}_{2}$ removal plant. The objective has been chosen to be minimizing the amine regeneration reboiler specific energy. The constraint function is the $\mathrm{CO}_{2}$ removal rate and the temperature in the reboiler. The objective is to have a temperature less than $120{ }^{\circ} \mathrm{C}$ in the reboiler, a commonly applied upper limit to avoid degradation of the amine, and to have more than $85 \%$ of the $\mathrm{CO}_{2}$ in the flue gas removed. However, other levels of removal will also be investigated. Bounds are applied to all factors/variables according to Table 2 . The results of the optimisation are summarised in Tables 4 and 5 .

The optimisation is performed with different strategies, the first one used DE as the only method. Three other optimisations are also performed where the optimum found by the $\mathrm{DE}$ algorithm is further polished with a local optimiser. Results for the following three polishing methods are shown trust-constr, COBYLA and SLSQP. The polishing runs are performed with the optimal settings found from the DE algorithm as an initial guess. Table 4 shows the optimal settings for all optimisation strategies, the objective function (specific energy requirement) at the optimum is also displayed, both as provided by the surrogate model response used in the optimisation but also calculated using the full simulation model. It is seen that all attempts to polish with a local optimiser seem to have an effect in terms of reducing the objective function to some extent. The following characteristics apply to the optimal settings: The MEA concentration is at the high bound, the minimum temperature approach in the $\mathrm{L} / \mathrm{R}$ heat exchanger as well as the flue gas temperature is at the low bound, the temperature of the lean amine has an approach of approx. $6.5^{\circ} \mathrm{C}$ to the flue gas temperature, the lean MEA rate has a flow rate of $345-360 \mathrm{~m}^{3} / \mathrm{h}$, the pressure in the regenerator (stripper/ reboiler) has a pressure of 1.83-1.85 bar and the boil-up ratio is approx. $0.13-0.14$.

The lean MEA flowrate, corresponding to an $\mathrm{L} / \mathrm{G}$ ratio of $2.17-2.27(\mathrm{~kg} / \mathrm{kg})$, is somewhat lower than the value of approx. $2.7(\mathrm{~kg} / \mathrm{kg})$ which is found to result in the lowest reboiler duty for a PCC application with flue gas having comparable $\mathrm{CO}_{2}$ concentrations [59]. One difference to the study of Agbonghae et al. [59] is a higher $\mathrm{CO}_{2}$ removal efficiency of $90 \%$ and an optimisation using a one-factorat-a-time approach. Simulations performed by Zhang and Chen [60] indicate an optimum $\mathrm{L} / \mathrm{G}$ ratio between 1.9 and $2.5(\mathrm{~kg} / \mathrm{kg})$ when simulating the experimental results of Mangalapally and Hasse [61] for a flue gas with comparable $\mathrm{CO}_{2}$ concentrations and removal efficiency.

The optimal stripper/reboiler pressure found is in good agreement with that found by Warudkar et al. [62], who demonstrated that a higher operating pressure of the 


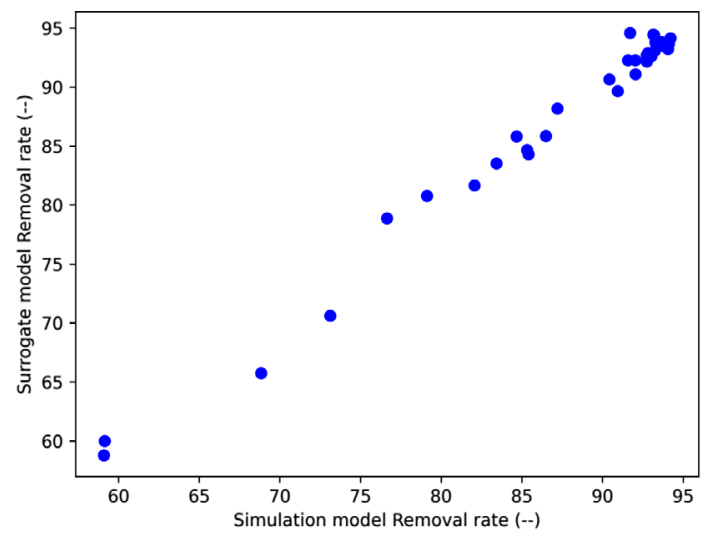

(a)

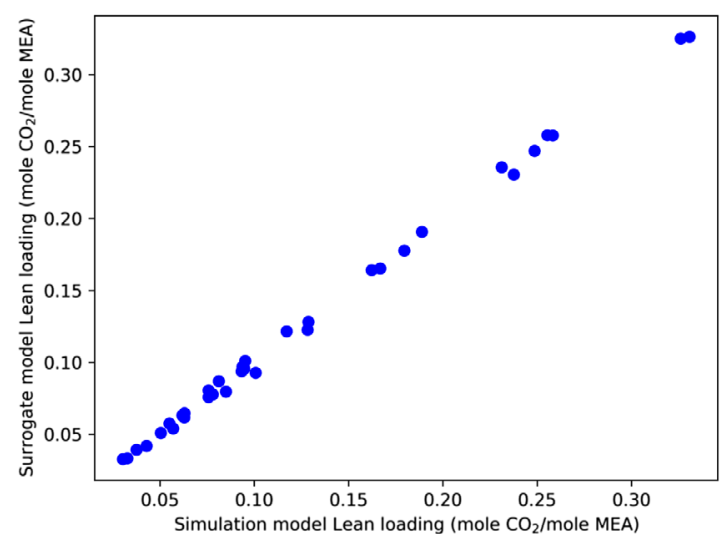

(c)

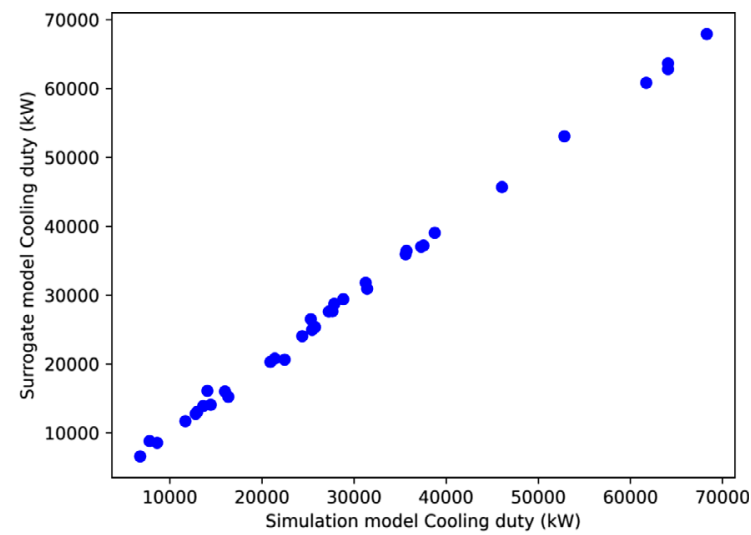

(b)

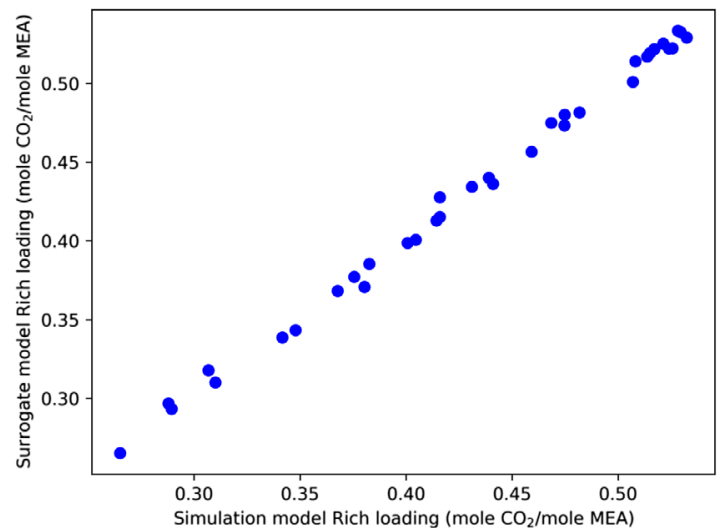

(d)

Fig. 3. Surrogate model response vs. full simulation model response for (a) $\mathrm{CO}_{2}$ removal rate, (b) total cooling duty, (c) $\mathrm{CO}_{2}$ loading in lean MEA and (d) $\mathrm{CO}_{2}$ loading in rich MEA.

Table 3. Validation of surrogate model performance. $n$-RMSE is the normalised root mean squared error, with normalisation by the mean.

\begin{tabular}{lcccc}
\hline Response & $R^{2}$ & $R_{\text {adj }}^{2}$ & RMSE & $n$-RMSE \\
\hline Specific energy consumption & 0.9987 & 0.9987 & 0.068 & 0.013 \\
Removal rate & 0.9873 & 0.9868 & 1.089 & 0.012 \\
Reboiler duty & 0.9997 & 0.9997 & 309.1 & 0.008 \\
Cooling duty & 0.9983 & 0.9982 & 713.1 & 0.025 \\
Regenerator temperature & 0.9986 & 0.9985 & 0.302 & 0.002 \\
Lean loading & 0.9985 & 0.9984 & 0.003 & 0.027 \\
Rich loading & 0.9970 & 0.9969 & 0.005 & 0.010 \\
\hline
\end{tabular}

stripper reboiler was beneficial for the reboiler specific energy requirement with an optimum between 1.75 and 2.0 bara in order not to exceed a reboiler temperature of $120^{\circ} \mathrm{C}$.

The minimum specific energy required is $3.41 \mathrm{MJ} / \mathrm{kg}$ $\mathrm{CO}_{2}$ for COBYLA and SLSQP. For the trust-constr the minimum is $3.398 \mathrm{MJ} / \mathrm{kg} \mathrm{CO}$, which is more or less the same. These values compare well with reported simulation based optimised values [8], (3.48 MJ/kg, 90\% removal efficiency) [10], (3.26, $85 \%$ removal efficiency), [10]
(3.65 $\mathrm{MJ} / \mathrm{kg}$, $85 \%$ removal efficiency). Øi reports that the calculated specific energy requirement depends on the model used, and that compared to Kent-Eisenberg, the Li-Mather model showed a reduced specific energy requirement accompanied by removal efficiency [24]. Zhang and Chen [60] demonstrate that an equilibrium model tends to under-predict the energy requirement compared to a rate based model due to an over-estimation of the amine capacity. An experimental value of 3.6 [63] is reported for MEA for PCC with $90 \%$ removal efficiency, and $3.63 \mathrm{MJ} / \mathrm{kg}$ for 
Table 4. Surrogate model response vs. full simulation model response for (a) $\mathrm{CO}_{2}$ specific energy consumption (for reboiler), (b) reboiler duty and (c) reboiler temperature.

\begin{tabular}{lcccccccccc}
\hline Method & $\begin{array}{c}\text { MEA } \\
\text { conc } \\
(\mathrm{w} / \mathrm{w} \%)\end{array}$ & $\begin{array}{c}\text { MEA } \\
\text { rate } \\
\left(\mathrm{m}^{3} / \mathrm{h}\right)\end{array}$ & $\begin{array}{c}\text { MEA } \\
\mathrm{dT}\end{array}$ & $\begin{array}{c}\left.{ }^{\circ} \mathrm{C}\right) \\
\mathrm{dT} \\
\left({ }^{\circ} \mathrm{C}\right)\end{array}$ & $\begin{array}{c}\text { Regen } \\
\text { pressure } \\
(\text { bar })\end{array}$ & $\begin{array}{c}\text { Boil-up } \\
\text { ratio } \\
(-)\end{array}$ & $\begin{array}{c}\text { Flue gas } \\
\text { temp. } \\
\left({ }^{\circ} \mathrm{C}\right)\end{array}$ & $\begin{array}{c}\text { Sur. Spec. } \\
\text { energy } \\
\left(\mathrm{MJ} / \mathrm{kg} \mathrm{CO}_{2}\right)\end{array}$ & $\begin{array}{c}\text { Sim. Spec. } \\
\text { energy }\end{array}$ & $\begin{array}{c}\text { Error } \\
(-)\end{array}$ \\
\hline DE & 29.8 & 359.2 & 6.69 & 5.1 & 1.85 & 0.134 & 40.0 & 3.428 & 3.421 & 0.002 \\
trust-constr & 30.0 & 345.5 & 6.54 & 5.1 & 1.83 & 0.141 & 40.0 & 3.398 & 3.407 & -0.002 \\
COBYLA & 30.0 & 359.2 & 6.54 & 5.0 & 1.85 & 0.132 & 40.0 & 3.410 & 3.370 & 0.012 \\
SLSQP & 30.0 & 359.2 & 6.54 & 5.0 & 1.85 & 0.132 & 40.0 & 3.410 & 3.370 & 0.012 \\
\hline
\end{tabular}

Table 5. Full simulation output responses using the optimal factor settings from optimisation using surrogate models.

\begin{tabular}{|c|c|c|c|c|c|c|}
\hline Method & $\begin{array}{c}\mathrm{CO}_{2} \text { removal } \\
(\%)\end{array}$ & $\begin{array}{l}\text { Reboiler duty } \\
(\mathrm{kW})\end{array}$ & $\begin{array}{c}\text { Cooler duty } \\
(\mathrm{kW})\end{array}$ & $\begin{array}{c}\text { Reboiler temp. } \\
\left({ }^{\circ} \mathrm{C}\right)\end{array}$ & $\begin{array}{l}\text { Lean loading } \\
\text { mole } \mathrm{CO}_{2} / \mathrm{m}\end{array}$ & $\begin{array}{l}\text { Rich loading } \\
\text { nole MEA }\end{array}$ \\
\hline $\mathrm{DE}$ & 85.27 & 24,555 & 11,127 & 119.9 & 0.201 & 0.518 \\
\hline trust-constr & 85.08 & 24,396 & 10,680 & 119.9 & 0.194 & 0.522 \\
\hline COBYLA & 85.39 & 24,217 & 10,344 & 119.9 & 0.207 & 0.522 \\
\hline SLSQP & 85.39 & 24,217 & 10,344 & 119.9 & 0.207 & 0.522 \\
\hline
\end{tabular}

$93 \%$ removal efficiency $[60,61]$ yet others report higher values [61,64]. Direct comparison with values from the present study with the work of others is difficult and ideally all relevant operating parameters shall be considered such as flue gas $\mathrm{CO}_{2}$ concentration, MEA concentration, $\mathrm{L} / \mathrm{G}$ ratio, stripper/reboiler pressure, reboiler temperature, temperature approaches, etc.

In Table 4 the specific energy is also calculated with the full simulation model using the optimum found from using the Kriging surrogates. As seen the specific energy calculated using the full simulation closely matches the results from the surrogates. It is interesting to note that for the full simulation model, the optimum found polishing with COBYLA/SLSQP is slightly better than the polishing with trust-constr. This indicates that the multi-dimensional hyper-surface of the objective function has been skewed to some extent due to an imperfect fit of the Kriging model. This might be minimised by increased sampling, and/or intelligent infill of additional data points for training the surrogate models. However, in the present case the information loss and inaccuracy of applying surrogate models for the optimisation are considered well within acceptable limits. In Table 5 the model responses found from the full simulation runs are also displayed, and it is evident that shifting from the surrogate to the full simulation model the main constraints are (still) met i.e. the $\mathrm{CO}_{2}$ removal is above $85 \%$ and the reboiler temperature is below $120{ }^{\circ} \mathrm{C}$. It is also seen from the results that the optimum values for the lean and rich amine loading are 0.19-0.21 and $0.518-0.522$, respectively. The latter value is in good agreement with [64] showing a generally decreasing trend for the specific energy requirement with the minimum energy requirement occuring as the rich loading approaches 0.55 mole $\mathrm{CO}_{2}$ per mole MEA. The lean loading is in agreement with results from Lee et al. [9], who also discovered an optimal moderate lean loading of approx. 0.19 for minimal power requirement. The difference between the two levels, which is equal to $0.31-0.33$, is in good agreement with [9] and also with the acid gas pick-up used in simplified engineering calculations [65].

\subsection{Sensitivities}

A sensitivity analysis is performed in order to investigate how sensitive the specific energy requirement is to changes in the independent variables. The sensitivity analysis is not performed as a one-factor at a time i.e. holding all other independent variables constant. Instead for each different setting of the variable investigated a full optimisation is performed with the differential evolution algorithm, allowing all the remaining variables to vary within their bounds (cf. Tab. 2) to achieve the minimum specific energy requirement. For each variable setting and associated optimisation the same constraints as used in the previous section i.e. a minimum $\mathrm{CO}_{2}$ removal rate of $85 \%$ and a maximum reboiler temperature of $120{ }^{\circ} \mathrm{C}$ are applied. The results of this sensitivity analysis are summarised in Figure 4.

As seen from Figure 4 the sensitivity increases in the following order lean amine to flue gas temperature approach, min. temperature approach in the $\mathrm{L} / \mathrm{R}$ heat echanger, flue gas temperature, MEA concentration, regenerator pressure and $\mathrm{L} / \mathrm{G}$ ratio. The temperature of lean amine relative to the temperature of the flue gas has very little influence on the specific energy requirement, meaning that this value can be set more freely and taking other considerations into account such as e.g. optimisation of heat recovery from lean amine or similar. The $\mathrm{L} / \mathrm{R}$ exchanger min. approach clearly favours an approach which is as small as possible, but the effect is moderate. In reality setting this parameter will also to a large extent be a trade-off with respect to the size and 


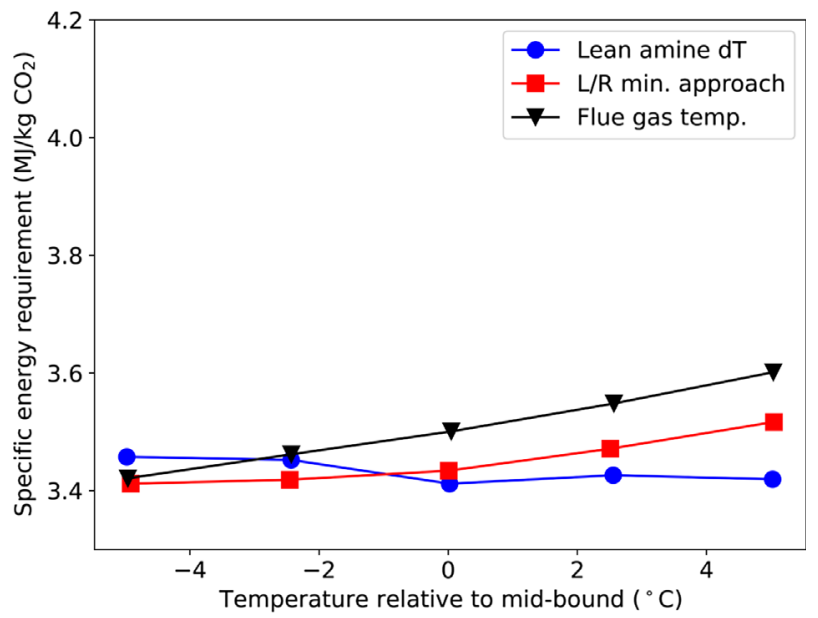

(a)

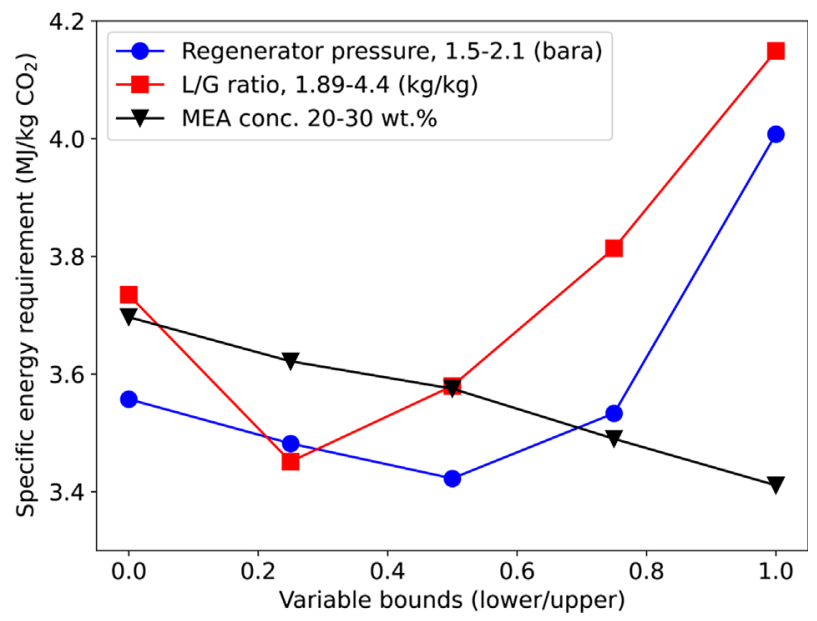

(b)

Fig. 4. Sensitivity analysis for independent variables (a) shows sensitivity of specific energy requirement to variations in temperature approaches of lean amine to flue gas, the $\mathrm{L} / \mathrm{R}$ heat exchanger and the flue gas temperature. Abcissa is the temperature relative to the mid bound cf. Table 2. Panel (b) shows sensitivity to changes in regenerator pressure, $\mathrm{L} / \mathrm{G}$ ratio and concentration of MEA solution. Corresponding abcissa bounds are given for each variable in the legend.

the cost of the heat exchanger equipment, and the CAPEX/NPV perspective may rule out a very low temperature approach [10]. The flue gas temperature is also optimal at the low bound, again this is determined by the amount of flue gas cooling/condensation upstream and this may also be constrained by CAPEX/NPV considerations. Further, this optimum may also be affected if an effect of stage efficiency as a function of temperature was included.

High amine concentrations are favoured to keep the specific energy requirement as low as possible. Again, the choice of amine concentration is a matter of other considerations such as the requirement for corrosion inhibitor, equipment and piping materials selection (carbon steel vs. stainless steel), etc. The two most important parameters are the $\mathrm{L} / \mathrm{G}$ ratio and the regenerator pressure and both

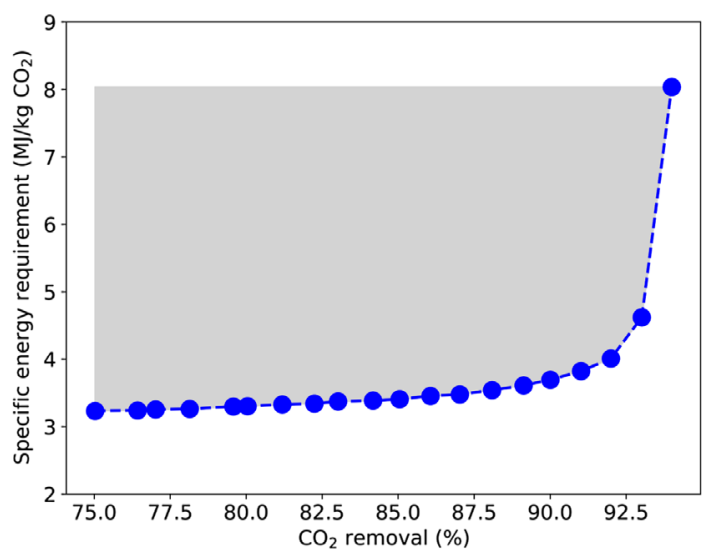

(a)

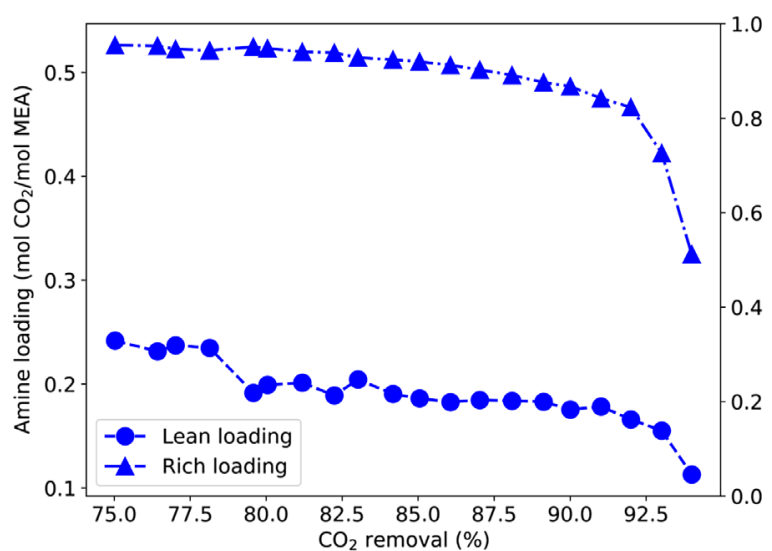

(b)

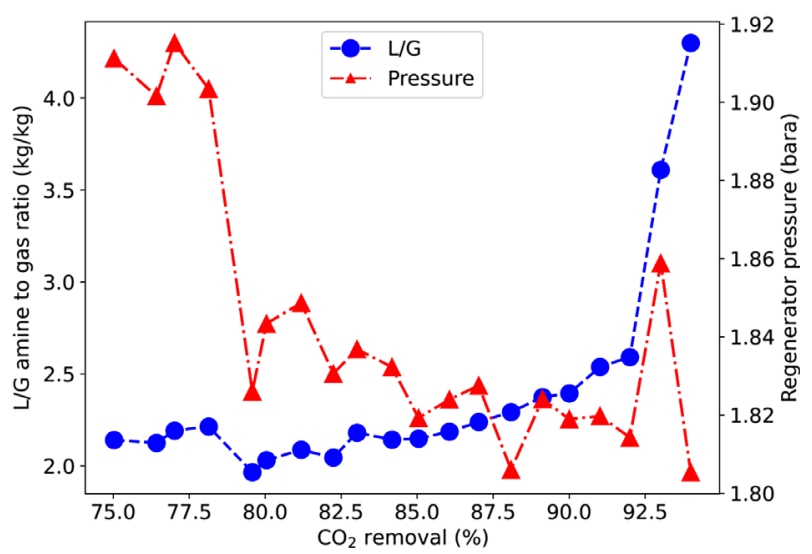

(c)

Fig. 5. Pareto optimal $\mathrm{CO}_{2}$ removal vs. specific energy requirement. Pareto frontier (a), corresponding lean and rich amine $\mathrm{CO}_{2}$ loading (b), liquid-to-gas ratio (lean amine/flue gas) and regenerator pressure for pareto optimal settings (c). The grey area in (a) represents possible nonoptimal solutions.

have a considerable impact on the specific energy requirement. Especially the L/G ratio may be subject to variations in off-design cases with lower than design flue gas flow. The results clearly indicate that the facilities can benefit from being able to adjust the amine flow to the actual flue gas flow by e.g. utilising variable frequency drive on the 
circulation pump or alternatively that the plant is flexible with respect to adjustments of other operating parameters in order to minimize the penalty of off-design operation.

\subsection{Pareto optimality}

An analysis is made investigating the minimum achievable specific energy requirement as a function of the $\mathrm{CO}_{2}$ removal efficiency i.e. a pseudo multi-objective optimisation seeking to maximise the $\mathrm{CO}_{2}$ removal efficiency at minimal specific energy requirements. The term pseudo is used to emphasise that this is not a true multi-objective optimisation, but merely a single objective optimisation, where the specific energy requirement is minimized, at increasing minimum $\mathrm{CO}_{2}$ removal efficiency (constraint). From this analysis a Pareto plot/frontier is constructed cf. Figure 5a.

As seen from Figure 5a the specific energy requirement is a weak function of the $\mathrm{CO}_{2}$ removal efficiency, yet steadily increasing, up to approx. $92 \%$ removal efficiency. From this point on, the specific energy requirement increased abruptly. This is qualitatively in agreement with experimental findings [64]. Figure 5b shows the lean and rich amine loading for the optimal settings, and it is observed that both lean and rich amine loading decreases as a function of removal efficiency, again in qualitative agreement with both experimental [64] and theoretical findings [11]. The difference being more or less constant up to the highest removal efficiencies, where the rich amine loading drops more than the lean loading. Figure $5 \mathrm{c}$ shows the required lean amine rate expressed as the liquid-to-gas $(\mathrm{L} / \mathrm{G})$ ratio as well as the optimal regenerator pressure. The $\mathrm{L} / \mathrm{R}$ ratio is somewhat fluctuating up to approx. $85 \%$ removal efficiency, from where it starts to increase monotonically. First, the increase is moderate up to around $92 \%$ removal efficiency, from where it increases abruptly. This trend is similar to the required specific energy. The regenerator pressure is between 1.80 and 1.92 bara for the full range of $\mathrm{CO}_{2}$ removal efficiencies, with a range of 1.80-1.86 being favoured once the $\mathrm{CO}_{2}$ is above $80 \%$.

\section{Conclusion}

It has been demonstrated that representing a complex process simulation of $\mathrm{CO}_{2}$ removal from flue gas using MEA as absorbent via a properly trained surrogate model, in this case using Kriging, is a very powerful tool for enabling black-box derivative free global optimisation in order to minimise the energy requirement for removing $\mathrm{CO}_{2}$. While seven factors or independent variables are used, the method can easily be expanded with even more variables [31]. The methods outlined in the present paper are not specific to Aspen HYSYS, but can be applied to any process simulator with a property package describing the $\mathrm{CO}_{2} / \mathrm{H}_{2} \mathrm{O} /$ Amine VLE behaviour and where the simulation is exposed via an API such as Windows COM or similar for effective data generation. The method can also be extended using a more rigorous rate-based model for even higher fidelity. Future works investigating other choices of surrogate models such as ANN, deep learning or similar would be very welcome, and could expand the versatility of the methods even further.

It is found that for meeting a $\mathrm{CO}_{2}$ removal efficiency of $85 \%$ for a flue gas containing 12.6 mole $\% \mathrm{CO}_{2}$ and a reboiler temperature limited to max. $120{ }^{\circ} \mathrm{C}$, an $\mathrm{L} / \mathrm{G}$ ratio of approx. $2.2(\mathrm{~kg} / \mathrm{kg})$ is optimal. This is accompanied by a stripper/regenerator pressure of 1.85 bara, a temperature of the flue gas at the lower bound, a temperature approach of the lean amine entering the absorber of $6.5{ }^{\circ} \mathrm{C}$ (to the flue gas temperature), a temperature approach in the $\mathrm{L} / \mathrm{R}$ heat exchanger of $5{ }^{\circ} \mathrm{C}$. The optimal lean and rich amine loading is approx. 0.21 and 0.52 (mole $\mathrm{CO}_{2} /$ mole MEA). Calculating the pareto frontier for minimum specific energy requirement at different $\mathrm{CO}_{2}$ removal efficiencies, demonstrates that $\mathrm{CO}_{2}$ efficiencies above approx. $92.5 \%$ is penalised hard with respect to increased energy demand, which occurs when the $\mathrm{L} / \mathrm{G}$ ratio exceeds $2.5(\mathrm{~kg} / \mathrm{kg})$.

Acknowledgments. The author would like to thank colleagues Christian Riber, Claus Hindsgaul, and Andrea Meroni from Ramboll Energy, Waste-to-Energy Department, for numerous enlightening discussions on carbon capture in relation to WtE. Language secretary Susanne Tolstrup, Ramboll Energy, Field Development, Process and Technical Safety Department is thanked for proof reading and language checking.

\section{References}

1 Rogelj J., Shindell D., Jiang K., Fifita S., Forster P., Ginzburg V., Handa C., Kheshgi H., Kobayashi S., Kriegler E., Mundaca L., Séférian R., Vilariño M.V. (2018) Mitigation pathways compatible with $1.5^{\circ} \mathrm{C}$ in the context of sustainable development, Chapter 2, in press, pp. 93-174.

2 Obersteiner M., Azar Ch., Kauppi P., Möllersten K., Moreira J., Nilsson S., Read P., Riahi K., Schlamadinger B., Yamagata Y., Yan J., van Ypersele J.-P. (2001) Managing climate risk, Science 294, 5543, 786-787. https://doi.org/ 10.1126 /science.294.5543.786b.

3 Moora H., Roos I., Kask U., Kask L., Ounapuu K. (2017) Determination of biomass content in combusted municipal waste and associated $\mathrm{CO}_{2}$ emissions in Estonia, Energy Proc. 128, 222-229. https://doi.org/10.1016/j.egypro.2017.09.059.

4 Riber Christian., Petersen C., Christensen T.H. (2009) Chemical composition of material fractions in Danish household waste, Waste Manage. 29, 4, 1251-1257. https://doi. org/10.1016/j.wasman.2008.09.013.

5 Xie N., Chen B., Tan C., Liu Z. (2017) Energy consumption and exergy analysis of mea-based and hydratebased $\mathrm{CO}_{2}$ separation, Indus. Eng. Chem. Res. 56, 51, 15094-15101. https://doi.org/10.1021/acs.iecr.7b03729.

6 Rochelle G.T. (2009) Amine scrubbing for $\mathrm{CO}_{2}$ capture, Science 325, 5948, 1652-1654. https://doi.org/10.1126/science.1176731.

7 Mores P., Scenna N., Mussati S. (2012) $\mathrm{CO}_{2}$ capture using monoethanolamine (MEA) aqueous solution: Modeling and optimization of the solvent regeneration and $\mathrm{CO}_{2}$ desorption process, Energy 45, 1, 1042-1058. https://doi.org/10.1016/ j.energy.2012.06.038. The 24th International Conference on Efficiency, Cost, Optimization, Simulation and Environmental Impact of Energy, ECOS 2011. 
8 Neveux T., Le Moullec Y., Corriou J.-P., Favre E. (2013) A rigorous optimization method of operating parameters for amine-based $\mathrm{CO}_{2}$ capture processes, Energy Proc. 37, 18211829. https://doi.org/10.1016/j.egypro.2013.06.060.

9 Lee A.S., Eslick J.C., Miller D.C., Kitchin J.R. (2013) Comparisons of amine solvents for post-combustion $\mathrm{CO}_{2}$ capture: A multi-objective analysis approach, Int. J. Greenhouse Gas Cont. 18, 68-74. https://doi.org/10.1016/j. ijggc.2013.06.020.

10 Øi L.E., Bråthen T., Berg C., Brekne S.K., Flatin M., Johnsen R., Moen I.G., Thomassen E. (2014) Optimization of configurations for amine based $\mathrm{CO}_{2}$ absorption using Aspen HYSYS, Energy Proc. 51, 224-233. https://doi.org/ 10.1016/j.egypro.2014.07.026.

11 Mores P.L., Godoy E., Mussati S.F., Scenna N.J. (2014) A NGCC power plant with a $\mathrm{CO}_{2}$ post-combustion capture option. Optimal economics for different generationcapture goals, Chem. Eng. Res. Des. 92, 7, 1329-1353. https://doi. org/10.1016/j.cherd.2013.11.013.

12 Wilhelm R., Esche E., Guetta Z., Menzel J., Thielert H., Repke J.-U. (2018) Model adaptation and optimization for the evaluation and investigation of novel amine blends in a pilot-plant scale $\mathrm{CO}_{2}$ capture process under industrial conditions, Chem. Eng. Trans. 69, 175-180. https://doi. org/10.3303/CET1869030.

13 Chen Y.-H., Shen M.-T., Chang H., Ho C.-D. (2019) Control of solvent-based post-combustion carbon capture process with optimal operation conditions, Processes 7, 6, 366. https://doi.org/10.3390/pr7060366.

14 Chung W., Lee J.H. (2020) Input-output surrogate models for efficient economic evaluation of amine scrubbing $\mathrm{CO}_{2}$ capture processes, Indus. Eng. Chem. Res. 59, 42, 1895118964. https://doi.org/10.1021/acs.iecr.0c02971.

15 Li F., Zhang J., Oko E., Wang M. (2017) Modelling of a postcombustion $\mathrm{CO}_{2}$ capture process using extreme learning machine, Int. J. Coal Sci. Technol. 40, 1, 33-40. https://doi. org/10.1007/s40789-017-0158-1.

16 Li F., Zhang J., Shang C., Huang D., Oko E., Wang M. (2018) Modelling of a post-combustion $\mathrm{CO}_{2}$ capture process using deep belief network, Appl. Therm. Eng. 130, 997-1003. https://doi.org/10.1016/j.applthermaleng.2017.11.078.

17 Chan V., Chan C. (2017) Learning from a carbon dioxide capture system dataset: Application of the piecewise neural network algorithm, Petroleum 3, 1, 56-67. https://doi.org/ 10.1016/j.petlm.2016.11.004.

18 Plesu V., Bonet J., Bonet-Ruiz A.E., Chavarria A., Iancu P., Llorens J. (2018) Surrogate model for carbon dioxide equilibrium absorption using aqueous monoethanolamine, Chem. Eng. Trans. 70, 919-924. https://doi.org/10.3303/CET1870154.

19 Nuchitprasittichai A., Cremaschi S. (2011) Optimization of $\mathrm{CO}_{2}$ capture process with aqueous amines using response surface methodology, Comput. Chem. Eng. 35, 8, 1521-1531. https://doi.org/10.1016/j.compchemeng.2011.03.016.

20 Dyment J., Watanasiri S., Acid gas cleaning using amine solvents: Validation with experimental and plant data (white paper), Aspentech. https://bit.ly/2SfwBai.

21 Peng D.-Y., Robinson D.B. (1976) A new two-constant equation of state, Indus. Eng. Chem. Fundamental 15, 1, 59 64. https://doi.org/10.1021/i160057a011.

22 Zhang Y., Que H., Chen C.-C. (2011) Thermodynamic modeling for $\mathrm{CO}_{2}$ absorption in aqueous MEA solution with electrolyte NRTL model, Fluid Phase Equilibria 311, 67-75. https://doi.org/10.1016/j.fluid.2011.08.025.
23 Øi L.E. (2010) $\mathrm{CO}_{2}$ removal by absorption: challenges in modelling, Mathematical and Computer Modelling of Dynamical Systems 160, 6, 511-533. https://doi.org/ $10.1080 / 13873954.2010 .491676$.

24 Øi L.E. (2007) Aspen HYSYS simulation of CO2 removal by amine absorption from a gas based power plant, in: P. Bunus, D. Fritzson, C. Führer (eds.), The 48th Scandinavian Conference on Simulation and Modeling (SIMS2007) Conference, Göteborg, October 30-31st 200\%, Linköping University, Lund University, Linköping University Electronic Press, Linköoping, Sweden.

25 Mckay M.D., Beckman R.J., Conover W.J. (2000) A comparison of three methods for selecting values of input variables in the analysis of output from a computer code, Technometrics 42, 1, 55-61. https://doi.org/10.1080/ 00401706.1979.10489755.

26 Morris M.D., Mitchell T.J. (1995) Exploratory designs for computational experiments, J. Stat. Plan. Infer. 43, 3, 381-402. https://doi.org/10.1016/0378-3758(94)00035-T.

27 Paulson C., Ragkousis G. (2015) pykriging: A python kriging toolkit, https://doi.org/10.5281/zenodo.21389.

28 Ibrahim M., Al-Sobhi S., Mukherjee R., AlNouss A. (2019) Impact of sampling technique on the performance of surrogate models generated with artificial neural network (ANN): A case study for a natural gas stabilization unit, Energies 12, 10, 1-2. https://doi.org/10.3390/en12101906.

29 Loeppky J.L., Sacks J., Welch W.J. (2009) Choosing the sample size of a computer experiment: A practical guide, Technometrics 51, 4, 366-376. https://doi.org/10.1198/ TECH.2009.08040.

30 Afzal A., Kim K.-Y., Seo J.W. (2017) Effects of Latin hypercube sampling on surrogate modeling and optimization, Int. J. Fluid Mach. Syst. 10, 240-253. https://doi.org/ 10.5293/IJFMS.2017.10.3.240.

31 Andreasen A. (2020) Applied process simulation-driven oil and gas separation plant optimization using surrogate modeling and evolutionary algorithms, ChemEng. 4, 1-2. https://doi.org/10.3390/chemengineering4010011.

32 AspenTech (2017) Aspen HYSYS customization, Ver. 10. Aspen Technology Inc.

33 Aspelund A., Gundersen T., Myklebust J., Nowak M.P., Tomasgard A. (2010) An optimization-simulation model for a simple lng process, Comput. Chem. Eng. 34, 10, 1606-1617. https://doi.org/10.1016/j.compchemeng.2009.10.018.

34 Caballero J.A., Grossmann I.E. (2008) An algorithm for the use of surrogate models in modular flowsheet optimization, AIChE J. 540, 10, 2633-2650. https://doi.org/10.1002/aic.11579.

35 Olsen E., Hooghoudt J.-O., Maschietti M., Andreasen A. (2021) Optimization of an oil and gas separation plant for different reservoir fluids using an evolutionary algorithm, Energy Fuels 35, 5392-5406. https://doi.org/10.1021/acs. energyfuels.0c04284.

36 Kim I.H., Dan S., Kim H., Rim H.R., Lee J.M., Yoon E.S. (2014) Simulation-based optimization of multistage separation process in offshore oil and gas production facilities, Indus. Eng, Chem. Res. 53, 21, 8810-8820. https://doi.org/ 10.1021/ie500403a.

37 Krige D. (1951) A statitical approach to some mine valuation and allied problems on the Witwatersrand, Master Thesis, University of the Witwatersrand.

38 Matheron G. (1963) Principles of geostatistics, Economic Geology 58, 8, 1246-1266. https://doi.org/10.2113/gsecongeo. 58.8.1246. 
39 Jones D.R. (2001) A taxonomy of global optimization methods based on response surfaces, J Global Optim. 21, 4, 345-383. https://doi.org/10.1023/A:1012771025575.

40 Ragkousis G.E., Curzen N., Bressloff N.W. (2016) Multiobjective optimisation of stent dilation strategy in a patientspecific coronary artery via computational and surrogate modelling, J Biomechanics 49, 2, 205-215. https://doi.org/ 10.1016/j.jbiomech.2015.12.013.

41 Paulson C. (2017) The rapid development of bespoke sensorcraft: a proposed design loop for small unmanned aircraft, PhD thesis, Faculty of Engineering and the Environment Computational Engineering and Design Group, University of Southampton.

42 Davis E., Ierapetritou M. (2007) A kriging method for the solution of nonlinear programs with black-box functions, AIChE J 53, 8, 2001-2012. https://doi.org/10.1002/aic. 11228.

43 Quirante N., Javaloyes J., Ruiz-Femenia R., Caballero J.A. (2015) Optimization of chemical processes using surrogate models based on a Kriging interpolation, in: K.V. Gernaey, J.K. Huusom, R. Ganii (eds.), 12th International Symposium on Process Systems Engineering and 25th European Symposium on Computer Aided Process Engineering, volume 37 of Computer Aided Chemical Engineering, Elsevier, NY, pp. 179-184. https://doi.org/10.1016/B978-0-444-63578-5.50025-6.

44 Andreasen A., Rønn Rasmussen K., Mandø M. (2018) Plant wide oil and gas separation plant optimisation using response surface methodology, IFAC-PapersOnLine 51, 8, 178-184. https://doi.org/10.1016/j.ifacol.2018.06.374

45 Storn R., Price K. (1997) Differential evolution - a simple and efficient heuristic for global optimization over continuous spaces, J. Global Optim. 11, 341-359. https://doi.org/ 10.1023/A:1008202821328.

46 Wormington M., Panaccione C., Matney K.M., Keith Bowen D. (1999) Characterization of structures from x-ray scattering data using genetic algorithms, Philos. Trans. A Math. Phys. Eng. Sci. 357, 1761, 2827-2848. https://doi.org/ 10.1098 /rsta.1999.0469.

47 Lampinen J. (2002) A constraint handling approach for the differential evolution algorithm, Proceedings of the 2002 Congress on Evolutionary Computation CEC'02 (Cat. No.02TH8600) 2, 1468-1473. https://doi.org/10.1109/ CEC.2002.1004459.

48 Virtanen P., Gommers R., Oliphant T.E., Haberland M., Reddy T., Cournapeau D., Burovski E., Peterson P., Weckesser W., Bright J., van der Walt S.J., Brett M., Wilson J., Millman K.J., Mayorov N., Nelson A.R.J., Jones E., Kern R., Larson E., Carey C.J., Polat I., Feng Y., Moore E.W., Vander Plas J., Laxalde D., Perktold J., Cimrman R., Henriksen I., Quintero E.A., Harris C.R., Archibald A.M., Ribeiro A.H., Pedregosa F., van Mulbregt P. (2020) SciPy 1.0: Fundamental algorithms for scientific computing in python, Nat. Methods 17, 261-272. https://doi.org/10.1038/ s41592-019-0686-2.

49 Kraft D. (1994) Algorithm 733: TOMP-Fortran modules for optimal control calculations, ACM Trans. Math. Softw. 20, 3, 262-281.

50 Byrd R.H., Hribar M.E., Nocedal J. (1999) An interior point algorithm for large-scale nonlinear programming, SIAM J. Optim. 9, 4, 877-900. https://doi.org/10.1137/ S1052623497325107.
51 Powell M.J.D. (1994) A direct search optimization method that models the objective and constraint functions by linear interpolation, pp. 51-67. https://doi.org/10.1007/978-94015-8330-5 4.

52 Powell M.J.D. (1998) Direct search algorithms for optimization calculations, Acta Numer. 7, 287-336. https://doi.org/ $10.1017 /$ S0962492900002841.

53 Harris C.R., Millman K.J., van der Walt S.J., Gommers R., Virtanen P., Cournapeau D., Wieser E., Taylor J., Berg S., Smith N.J., Kern R., Picus M., Hoyer S., van Kerkwijk M.H., Brett M., Haldane A., Del Río J.F., Wiebe M., Peterson P., Gérard-Marchant P., Sheppard K., Reddy T., Weckesser W., Abbasi H., Gohlke C., Oliphant T.E. (2020) Array programming with NumPy, Nature 585, 7825, 357-362. https://doi. org/10.1038/s41586-020-2649-2.

54 McKinney Wes. (2010) Data structures for statistical computing in python, in: S. van der Walt, J. Millman (eds.), Proceedings of the 9th Python in Science Conference, pp. 51-56.

55 Seabold S., Perktold J. (2010) Statsmodels: Econometric and statistical modeling with python, in: 9th Python in Science Conference, 2010.

56 Deutsch J.L., Deutsch C.V. (2012) Latin hypercube sampling with multidimensional uniformity, J. Stat. Plan. Infer. 142, 3, 763-772. https://doi.org/10.1016/j.jspi.2011.09.016.

57 Hammond M. (2020) pywin32. https://github.com/mhammond/pywin32.

58 Hunter J.D., Matplotlib A. (2007) 2D graphics environment, Comput. Sci. Eng. 9, 3, 90-95. https://doi.org/10.1109/ MCSE.2007.55.

59 Agbonghae E.O., Hughes K.J., Ingham D.B., Ma L., Pourkashanian M. (2014) Optimal process design of commercialscale amine-based $\mathrm{CO}_{2}$ capture plants, Indust. Eng. Chem. Res. 53, 38, 14815-14829. https://doi.org/10.1021/ie5023767.

60 Zhang Y., Chen C.-C. (2013) Modeling $\mathrm{CO}_{2}$ absorption and desorption by aqueous monoethanolamine solution with aspen rate-based model, Energy Proc. 37, 1584-1596. https://doi.org/10.1016/j.egypro.2013.06.034.

61 Mangalapally H.P., Hasse H. (2011) Pilot plant study of post-combustion carbon dioxide capture by reactive absorption: Methodology, comparison of different structured packings, and comprehensive results for monoethanolamine, Chem. Eng. Res. Des. 89, 8, 1216-1228. https://doi.org/ 10.1016/j.cherd.2011.01.013.

62 Warudkar S.S., Cox K.R., Wong M.S., Hirasaki G.J. (2013) Influence of stripper operating parameters on the performance of amine absorption systems for post-combustion carbon capture: Part I. high pressure strippers, Int. J. Greenhouse Gas Cont. 16, 342-350. https://doi.org/ 10.1016/j.ijggc.2013.01.050.

63 Knudsen J.N., Jensen J.N., Vilhelmsen P.-J., Biede O. (2009) Experience with $\mathrm{CO}_{2}$ capture from coal flue gas in pilot-scale: Testing of different amine solvents, Energy Procedia 1, 1, 783-790. https://doi.org/10.1016/j.egypro.2009.01.104.

64 Mangalapally H.P., Notz R., Hoch S., Asprion N., Sieder G., Garcia H., Hasse H. (2009) Pilot plant experimental studies of post combustion $\mathrm{CO}_{2}$ capture by reactive absorption with mea and new solvents, Energy Proc. 1, 1, 963-970. https://doi.org/10.1016/j.egypro.2009.01.128.

65 GPSA (2012) GPSA Engineering Data Book (SI version), 13th edn., Gas Processors Suppliers Association, Tulsa, Oklahoma. 